\title{
Field estimates of planktonic larval duration in a marine invertebrate
}

\author{
Scott C. Burgess ${ }^{1,2, *}$, Dustin J. Marshall ${ }^{1}$ \\ ${ }^{1}$ School of Biological Sciences, University of Queensland, Brisbane, Queensland 4072, Australia \\ ${ }^{2}$ CSIRO Marine and Atmospheric Research, Cleveland, Queensland 4163, Australia
}

\begin{abstract}
Planktonic larval durations (PLDs) affect the ecology and evolution of benthic marine populations through their effects on dispersal distance, the spread of sibling larvae, the level of larval mortality, and population connectivity. Despite the importance of PLDs, field estimates of PLDs in marine invertebrates are rare and restricted to specific taxa. The size of the first postmetamorphic feeding structure (the ancestrula lophophore) in Bugula neritina has been shown previously to decline with increases in larval duration. We hypothesised that if the relationship between larval duration and the size of the ancestrula lophophore can be estimated in the laboratory, then it should be possible to infer the PLD of $B$. neritina settlers in the field. We manipulated the length of the larval period in the laboratory and quantified the relationship between larval duration and the volume of the ancestrula lophophore. We then measured the size of lophophores in field-settled individuals at 2 sites on multiple days over a 2 yr period, and predicted their planktonic durations based on our laboratory-derived classifications. The average percentage of individuals in the field with short ( 0 to $1.5 \mathrm{~h}$ ), intermediate (1.5 to $6.5 \mathrm{~h}$ ), and long (6.5 to $32 \mathrm{~h}$ ) PLDs was 54,27 , and $19 \%$, respectively. Despite being competent to settle upon release from the colony, a significant proportion of settlers in the field experienced metamorphic delays that would incur significant post-settlement costs. Furthermore, there was a positive relationship between settlement density and the proportion of settlers in any one cohort that had experienced short PLDs. The extended planktonic periods that we predicted are likely to affect the dynamics of adult populations directly via reductions in settlement density and indirectly via reductions in the postsettlement performance of individuals that experienced a metamorphic delay before settling.
\end{abstract}

KEY WORDS: Delayed metamorphosis $\cdot$ Dispersal $\cdot$ Larval quality $\cdot$ Larval mortality $\cdot$ Population connectivity Resale or republication not permitted without written consent of the publisher

\section{INTRODUCTION}

The length of time that benthic marine invertebrate larvae spend in the plankton remains poorly understood despite $>50 \mathrm{yr}$ of study (Thorson 1950, Vance 1973, Strathmann 1985, Morgan 1995, Pechenik et al. 1998, Levin 2006). Given their small size, marine larvae are notoriously hard to track in nature, so the amount of time that larvae spend in the plankton is extremely challenging to estimate directly. Fish ecologists overcome this challenge by using fish otoliths to estimate planktonic larval duration (PLD; Pannella 1971, Brothers et al. 1983, Victor 1986b) and in some instances, even natal origin (Swearer et al. 1999, Cowen et al. 2006). Unfortunately, the majority of marine invertebrate larvae do not have an equivalent 'time-keeper' (though see e.g. Laptikhovsky et al. 1993, Villanueva et al. 2003, Gonzalez et al. 2010), so estimating planktonic durations for most marine invertebrates is much more difficult. Despite the difficulties, estimates of planktonic durations are essential for understanding and managing marine populations. 
PLDs have a number of important implications for the ecology and evolution of marine populations. Planktonic durations place a maximum limit on the distance that offspring can disperse from their sessile or 'site-attached' parents, which can influence population connectivity, population persistence, and the scale of local adaptation (Holt \& Gaines 1992, Lenormand 2002, Palumbi 2003, Botsford et al. 2009). The length of the larval period also influences the spread of sibling larvae relative to each other (Strathmann 1974, Palmer \& Strathmann 1981, Ronce 2007). PLDs affect not only how far larvae move, but also how much mortality they are likely to suffer. The plankton is thought to be a risky place for small, relatively unprotected larvae, and mortality rates can be high and longer planktonic periods probably entail significant mortality costs (Strathmann 1985, Rumrill 1989, Morgan 1995). If daily mortality rates $(m)$ are constant, the probability of surviving decreases exponentially with time $(t)$ as $\mathrm{e}^{-m t}$. In the absence of estimates of the planktonic period, however, it remains difficult to estimate how much mortality occurs in the larval stage relative to other stages.

PLDs also have post-settlement consequences by influencing the condition of individuals at settlement (Sponaugle \& Cowen 1997, Pechenik 2006). In particular, an increasing number of studies have shown that delaying metamorphosis in species with nonfeeding larvae reduces post-settlement performance (e.g. Woollacott et al. 1989, Pechenik \& Cerulli 1991, Pechenik et al. 1998, Qian \& Pechenik 1998, Wendt 1998). While the precise mechanism for such links between life-history stages remains unknown, it seems likely that the depletion of limited larval energy reserves in order to extend the planktonic period is used at the expense of that which could be used for metamorphosis and post-settlement growth (Jaeckle 1994, Hunter et al. 1998, Wendt 2000, Marshall et al. 2003, Bennett \& Marshall 2005). For example, delaying metamorphosis in the larvae of some species of gastropod has differential effects that depend on whether individuals produce feeding or non-feeding larval forms (Miller 1993, Botello \& Krug 2006). Delaying metamorphosis results in nonfeeding larvae becoming increasingly responsive to settlement cues as they age or having lower performance after metamorphosis, whereas the settlement responses and post-settlement performance of feeding larvae change little with larval age (Miller 1993, Botello \& Krug 2006). The post-settlement consequences of prolonged larval periods in non-feeding larvae can be quite severe. Individuals that experience an extended duration can suffer higher mortal- ity, lower growth and even lower reproductive rates (Woollacott et al. 1989, Pechenik \& Cerulli 1991, Pechenik et al. 1998, Qian \& Pechenik 1998, Wendt 1998, Marshall et al. 2003). In fact, the effects of delaying metamorphosis can be so strong, they can outweigh the effects of initial population density on the total reproductive output of populations (Burgess \& Marshall 2011a). In a recent study, we showed that populations founded by a single, undelayed individual had the equivalent reproductive output to a population founded by 30 delayed individuals (Burgess \& Marshall 2011a). While this, and other studies, suggest that delays in metamorphosis have the potential to influence subsequent population dynamics, the dearth of estimates of larval duration in the field hampers our ability to estimate the importance of these effects in the field.

In response to the need for estimates of planktonic durations in the field, a range of approaches have been developed. Some researchers have followed individual larvae directly and simultaneously estimated planktonic mortality, larval movement, and planktonic duration (Gerrodette 1981, Olson 1985, Young 1986, Davis \& Butler 1989, Bingham \& Young 1991, Stoner 1992). Such approaches are valuable, but are necessarily restricted to species with conspicuous larvae with relative short larval durations (e.g. ascidians). More widespread are indirect approaches to estimating planktonic durations, such as molecular genetics techniques (Miller 1998, Jones et al. 2005) or biophysical models (Largier 2003, Siegel et al. 2003). These approaches are partially hampered by the influence of post-settlement processes and provide more information on dispersal distances than planktonic durations. Another approach to estimate larval durations and the extent of delayed metamorphosis uses differences in the morphology of larvae (Pechenik 1986, Takami et al. 2006). For example, larvae of 2 species of a marine gastropod (Crepidula fornicata and $C$. plana) form a conspicuous flat brim around their shells once obtaining metamorphic competency. Pechenik (1986) utilised this shell brim to estimate that 5 to $20 \%$ of larvae in the plankton delayed metamorphosis. Similarly, Takami et al. (2006) utilised a linear relationship between larval age and the number of rows of radular teeth in the abolone Haliotis discus hannai to predict that larval durations in the field were in the order of 4 to $6 \mathrm{~d}$ for this species. Morphological approaches to estimating larval duration avoid confounding settlement with recruitment and allow the estimation of not only the mean planktonic duration but also variation in planktonic duration. Despite the potential utility of mor- 
phological-based indicators of larval durations in marine invertebrates, such studies remain rare.

One potential indictor of larval duration in species with nonfeeding larvae is the size of the first juvenile feeding structure. In at least 2 species, an ascidian (Diplosoma listerianum, Marshall et al. 2003) and a bryozoan (Bugula neritina, Wendt 1996), extending the larval period decreases the size of the first zooid's feeding structure. Thus, if the relationship between the larval duration and the size of the first juvenile feeding structure can be estimated in the laboratory, then it should be possible to infer the PLD of settlers in the field. In the present study, we sought to use such an approach to estimate the length of the planktonic period of field settlers in $B$. neritina. We first manipulated the length of the larval period in the laboratory and quantified the relationship between larval duration and the ancestrula lophophore volume. We used cross-validation methods to classify individuals into larval duration categories based on lophophore volume. We then measured the size of lophophores in field-settled individuals at 2 sites on multiple days between February 2007 and June 2009 and predicted their planktonic durations based on our laboratory-derived classifications. We found that PLDs in the field were highly variable among cohorts and a significant proportion of larvae spent extended periods of time $(>6.5 \mathrm{~h})$ in the plankton such that they were likely to incur significant reductions in performance after metamorphosis.

\section{MATERIALS AND METHODS}

\section{Laboratory methods}

Larvae were obtained from reproductively mature colonies of Bugula neritina collected from the sides of floating docks at 2 sites in Brisbane, Queensland, Australia: Moreton Bay Boat Club (Scarborough Boat Harbour, $27^{\circ} 27.0^{\prime} \mathrm{S}, 153^{\circ} 11.4^{\prime} \mathrm{E}$, in Redcliffe) and the East Coast Marina (Manly Boat Harbour, 27²7.6' S, $153^{\circ} 11.2^{\prime} \mathrm{E}$, in Manly). These 2 sites are privately owned marinas with limited public access and are separated by about $30 \mathrm{~km}$ of coastline. Water temperature at these 2 sites varies from ca. $15^{\circ} \mathrm{C}$ in winter to ca. $27^{\circ} \mathrm{C}$ in summer (Burgess \& Marshall 2011b).

Colonies were spawned and larvae settled in the laboratory using standard techniques (Marshall \& Keough 2003). Briefly, colonies were held in dark, aerated aquaria for $48 \mathrm{~h}$, at concurrent water temperatures to that in the field, before being exposed to bright light to stimulate larval release. Colonies were spawned in individual containers to ensure larvae from multiple colonies were used. Since larvae are competent to settle upon release, larval duration was manipulated by delaying metamorphosis, as occurs in the absence of suitable habitat (Marshall \& Keough 2003, Burgess et al. 2009, Burgess \& Marshall 2011a). Metamorphosis was delayed by placing larvae in $200 \mathrm{ml}$ of $0.45 \mu \mathrm{m}$ filtered seawater in four $500 \mathrm{ml}$ glass bottles on a mechanical roller mixer (Model 205-RM, Hwashin Technology), which slowly rolled the bottle (40 rpm) so that larvae were prevented from attaching. About a quarter of the water in each bottle was exchanged every few hours. After the prescribed larval duration (which varied from 0 to $32 \mathrm{~h})$, larvae were randomly taken from each of the 4 bottles and placed in a drop of water onto roughened, bio-filmed transparency film (overhead projector sheets) to settle. Once attached, individuals were marked by drawing a circle around them to make sure there was no mortality during metamorphosis. Settlers were given $2 \mathrm{~d}$ to metamorphose (at temperatures similar to that in the field at that time of year), at which point lophophore measurements were taken. Individual settlers were removed by cutting out a $\sim 70 \times 70 \mathrm{~mm}$ square around the settler. Settlers were then oriented horizontally and photographed with a camera (PixelLINK Capture SE, v. 1.0) mounted on a dissecting microscope. Following Wendt (1996), lophophore volume and surface area was estimated as:

$$
\begin{aligned}
& \text { Heigth, } h=\sqrt{c^{2}-\left(1 / 4(a-b)^{2}\right)} \\
& \text { Volume }=\pi h\left(a^{2}+a b+b^{2}\right) / 12 \\
& \text { Surface area }=\pi c(a+b) / 2
\end{aligned}
$$

where $a$ is the diameter of the lophophore at the crown, $b$ is the diameter of the lophophore at the base, and $c$ is tentacle length (Fig. 1). Similar results were obtained for lophophore volume and surface area, so only volumes are presented here. In order to estimate other sources of variability in lophophore size, we also accounted for larval volume (Kosman \& Pernet 2011). In a separate experiment (repeated 3 times at Manly), the relationship between larval volume and lophophore volume was determined by measuring the cross-sectional area of larvae $(n=77)$ from photographs taken prior to settlement (Marshall $\&$ Keough 2003). Cross-sectional area (a) was converted to volume as $4 / 3 \pi \sqrt{a / \pi}^{3}$. We found that, in contrast to a northern hemisphere population (Kosman \& Pernet 2011), post-metamorphic lophophore sizes were not significantly affected by larval volume (see 'Results'). 


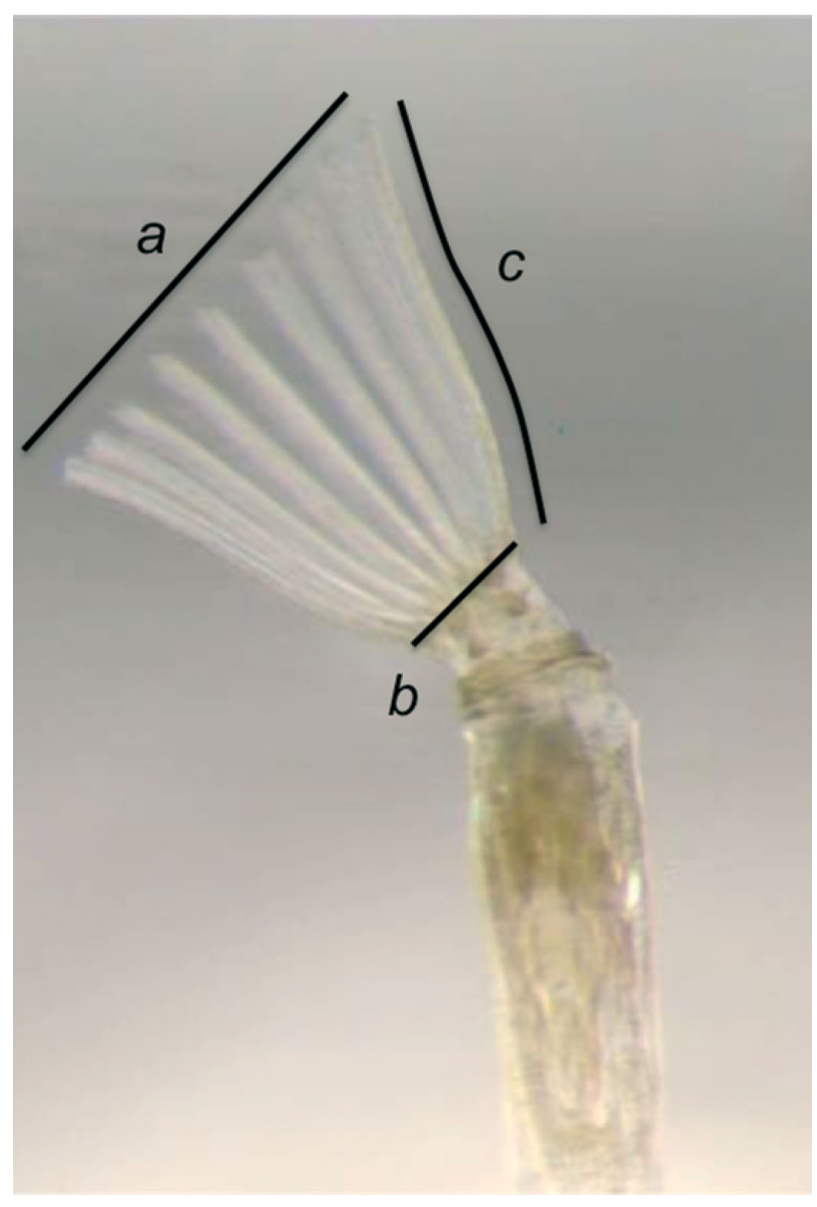

Fig. 1. Bugula neritina. Photograph of an ancestrula showing the measurements taken to estimate lophophore volume; a: diameter of the lophophore at the crown, b: diameter of the lophophore at the base, and c: tentacle length

\section{Field methods}

To sample lophophore sizes and settler density in the field, 16 roughened settlement plates $(21 \times 21 \mathrm{~cm}$ transparency film) were attached to the undersides of 4 backing panels (4 settlement plates per backing panel). Backing panels were attached to floating pontoons and hung $\sim 1 \mathrm{~m}$ below the water surface. On each replicate day (see 'Sampling regime' below), settlement plates were deployed for $24 \mathrm{~h}$. In the field, Bugula neritina release larvae during daylight hours (Kosman \& Pernet 2009, S. C. Burgess unpubl. data); the majority of larvae tend to settle in the morning and do not settle during the night (Whitlatch \& Osman 1998, S. C. Burgess unpubl. data). After 24 h, settlers were circled with a pencil in the field and then transported back to the laboratory and stored in insulated aquaria. Mortality of individuals during transport and until lophophore measurements were made was minimal ( $<1 \%$; data not shown), so we were confident that our methods estimated settlement and were relatively unaffected by post-metamorphic mortality. Settlement plates were transferred and stored in $250 \mu \mathrm{m}$ filtered seawater so that no additional settlement could occur. Two days after collection of settlement plates, lophophore sizes of settlers were estimated the same way as described in 'Laboratory methods', so that measurement of lophophore volumes were consistent between settlers in the laboratory and the field. On most days, the lophophore volume of every settler was measured. On 2 d at Redcliffe, settlement totalled 467 and 629 individuals on each day and was too high to measure every individual, so lophophore volumes were measured on 45 and 38 (respectively) randomly chosen individuals.

\section{Sampling regime}

All laboratory and field experiments were repeated multiple times and we refer to each repeat as a run. In each run of the laboratory experiments, larvae were obtained from different batches of adult colonies collected on different days. Each run in field experiments was done on a different day. Sampling for both the laboratory and field data sets was done over a period of 28 mo from February 2007 to June 2009 (Table 1). The lophophores of 309 and 505 individuals from the laboratory and field, respectively, were measured. The laboratory data set consisted of a total of 8 runs. The field data set consisted of a total of 25 runs (i.e. sampling days).

\section{Statistical analyses}

The relationship between larval duration and lophophore volume in the laboratory was analysed

Table 1. Bugula neritina. Number of runs performed and total number of individuals sampled (n) at each site for the laboratory and field data sets

\begin{tabular}{|llccccc|}
\hline Site & Dates & \multicolumn{2}{c}{$\begin{array}{c}\text { Laboratory } \\
\text { No. of }\end{array}$} & n & \multicolumn{2}{c|}{ Field } \\
No. of & $\mathrm{n}$ \\
runs & & & \multicolumn{2}{c}{ runs } \\
\hline Manly & Feb-May 2007 & 4 & 222 & 7 & 300 \\
& Apr-May 2009 & 1 & & 4 & \\
Redcliffe & Apr-May 2008 & 3 & 87 & 9 & 205 \\
& Jun 2009 & 0 & & 5 & \\
Total & & & 309 & & 505 \\
\hline
\end{tabular}


using analysis of covariance (ANCOVA), where runs within sites was treated as a random factor. In some runs, larval duration was not manipulated for as long as it was in other runs (i.e. there were non-overlapping covariate ranges), so our analyses of slope heterogeneity only included larval durations of $<12 \mathrm{~h}$. The relationships between larval duration and larval size in the laboratory, and between the proportion of settlers with short dispersal durations and settlement density in the field, was analysed using ANCOVA. The analysis with larval size included run (3 runs) as a random factor and the analysis on settlement density included sites (Manly or Redcliffe) as a random factor. Analyses were performed in $\mathrm{R}$ (v. 2.10.1). Hypothesis tests were performed in Systat 12.0.

The overall statistical approach to predict planktonic durations in the field was to first create a 'calibration' data set using the known relationship between larval duration and lophophore volume from the laboratory data set (where larval duration was manipulated) and then use this reference model to predict the PLD of settlers in the field based on the volume of their lophophores. The prediction of PLDs in the field was done in 3 stages. The last 2 stages were very similar to the approach used in Becker et al. (2007) to successfully identify origins of Mytilus spp. settlers based on shell chemistry. Through trying various other 'inverse prediction' methods, we found that predicting PLD categories reduced the uncertainty of predictions compared to predicting the actual PLD value (S. C. Burgess unpubl. data).

In the first stage, regression trees were used to partition lophophore volume into homogeneous groups based on larval durations (using the 'rpart' function in $\mathrm{R}$ and following the methods in De'ath \& Fabricius 2000, Venables \& Ripley 2002). Lophophore volume was log-transformed and additive differences among runs were standardised prior to analyses after finding no interactive effects of run (see 'Results'; Quinn \& Keough 2002). Regression trees find groups by minimising the least-squares deviation in lophophore volume. Each group was then characterised by the mean value of lophophore volume and the range of larval durations that define it. The final regression tree used was pruned back in order to avoid overfitting or including random variation and systematic biases into predictions (De'ath \& Fabricius 2000, Venables \& Ripley 2002). In the second stage, we determined the robustness of the 3 larval duration categories by using linear discriminant analysis (LDA; using the 'lda' function in $\mathrm{R}_{i}$ Venables \& Ripley 2002) and jack-knifed cross-validation success. In the third stage, we used the LDA classification model for the laboratory data set (the second stage) to classify the lophophore volumes of settlers into the field (i.e. new observations) into larval duration categories (Becker et al. 2007).

\section{RESULTS}

\section{Laboratory results}

In the laboratory, there was a negative relationship between larval duration and lophophore volume $\left(F_{1,300}=168.53, \mathrm{p}<0.001 ;\right.$ Fig. 2$)$. Both the intercept and slope of the regression (using individuals; Fig. 2) were similar to that obtained in Wendt (1996) (using the mean of 8 to 32 individuals in 5 replicate dishes). There was no interaction between larval duration and runs within each site $\left(F_{7,245}=1.38, \mathrm{p}=0.22\right)$, but average lophophore volume differed among runs within each site $\left(F_{7,245}=17.67, \mathrm{p}<0.001\right)$.

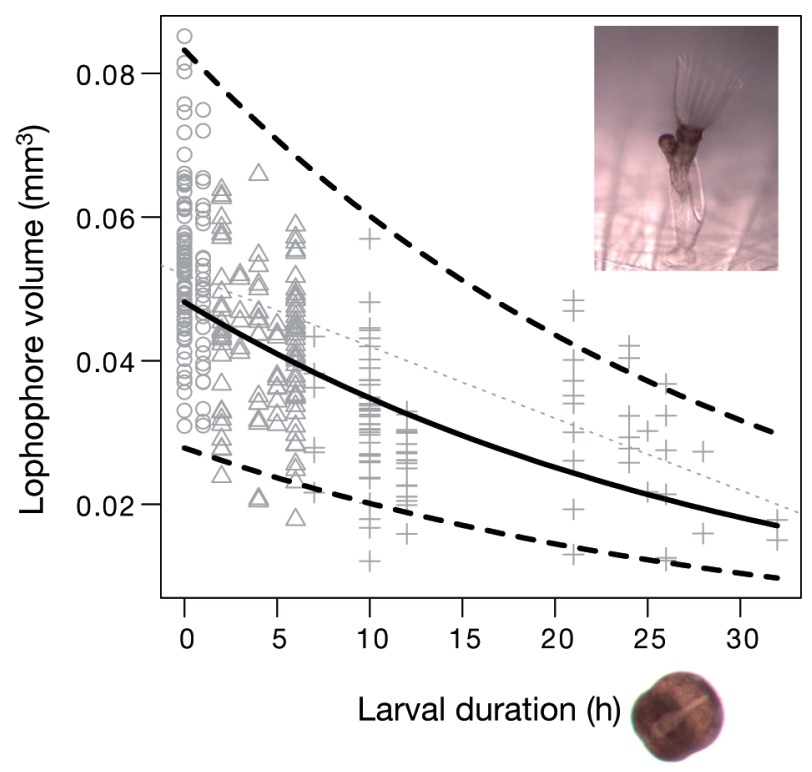

Fig. 2. Bugula neritina. Relationship between larval duration (a larva is shown on $x$-axis) and ancestrular lophophore volume (photo insert). Larval duration was manipulated in the laboratory and lophophore volume was measured soon after individuals had settled and metamorphosed (see 'Materials and methods'). Each dot represents a single individual; shapes represent the 3 categories identified from regression tree analysis (see Fig. 3). Dashed lines show 95\% predictive intervals estimated from a linear model on run-standardised data (see 'Materials and methods'). Lophophore volume was log-transformed for analysis, but presented here on the original scale of measurement. $\ln (y)=-3.03$ to $-0.03 x_{i} \mathrm{r}^{2}=0.40$. For comparison, the grey dotted line shows the relationship for B. neritina from California in Wendt (1996). $\bigcirc=$ short $(0-$ $1.5 \mathrm{~h}), \triangle=$ intermediate $(1.5-6.5 \mathrm{~h})$, and $+=\operatorname{long}(6.5-32 \mathrm{~h})$ 
Table 2. Bugula neritina. Analysis of covariance (ANCOVA) on the relationship between larval volume in 3 runs with lophophore volume. Lophophore volume differed among runs (different batches of colonies on different days), but did not change with larval volume $(\mathrm{n}=77$ larvae). The interaction between larval volume and run was removed after finding it was not significant $\left(F_{2,71}=0.15, \mathrm{p}=0.86\right)$

\begin{tabular}{|lrlcl|}
\hline Source & df & MS & $F$ & $\mathrm{p}$ \\
\hline Larval volume & 1 & 0.0000885 & 0.37 & 0.54 \\
Run & 2 & 0.00164 & 6.88 & 0.002 \\
Residual & 73 & 0.00024 & & \\
\hline
\end{tabular}

We found no relationship between larval volume and the ancestrula lophophore volume, though there were differences in the average lophophore volume among the 3 runs (Table 2).

\section{Success of the reference model}

The regression tree analysis on larval duration and lophophore volume from the laboratory data set yielding the lowest cross-validated error rate had 3 nodes (Fig. 3). The 3 groupings were short $(<1.5 \mathrm{~h})$, intermediate (1.5 to $6.5 \mathrm{~h})$, and long (6.5 to $32 \mathrm{~h}$ ) larval periods. LDA on lophophore volume of Bugula neritina in the laboratory was sufficient to discriminate among the 3 dispersal duration categories identified from the regression tree (Wilk's lambda $=0.51$, $F_{2,306}=145.6, \mathrm{p}<0.001 ;$ Table 3). Average classification success for each dispersal duration category was $63 \%$ (range: 44 to $75 \%$ ). Classification success was greatest for the shortest and longest larval duration category.

\section{Field estimates of PLD}

Across all sites and times, the average percentage $( \pm 95 \% \mathrm{CI})$ of individuals in the field with short (0 to $1.5 \mathrm{~h}$ ), intermediate (1.5 to $6.5 \mathrm{~h})$, and long (6.5 to $32 \mathrm{~h})$ PLDs was 53.86\% ( \pm 20.37$)$, $27.36 \%( \pm 18.22)$, and $18.79 \%( \pm 15.96)$, respectively (Fig. 4). There was, however, considerable variation in the proportions of individuals in each PLD category among days (grey lines in Fig. 4). On some days, the proportion of individuals with intermediate (1.5 to $6.5 \mathrm{~h})$ or long (6.5 to $32 \mathrm{~h}$ )

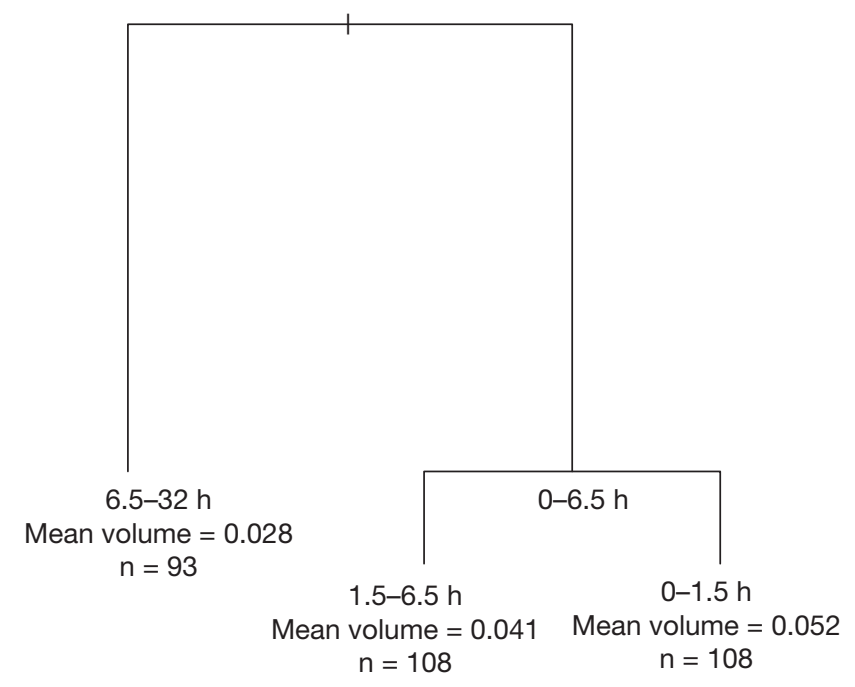

Fig. 3. Bugula neritina. Regression tree analysis separating measurements of lophophore volume into dispersal duration categories, where dispersal duration was manipulated in the laboratory. Splits that provide the best discrimination between larval durations are those with the longest branches. These 3 categories of lophophore volume were used to predict dispersal durations from the lophophore volumes of individuals that settled in the field

PLDs was greater than that for shorter PLDs. The proportion of individuals in each PLD category did not differ between the 2 sites $\left(F_{1,65}<0.001\right.$, p < 0.001).

Settlement densities were exceptionally high (662 and 891 settlers $\mathrm{m}^{-2}$ ) on $2 \mathrm{~d}$ at Redcliffe at the end of the sampling period and were statistical outliers. When these $2 \mathrm{~d}$ were included in the analysis (thereby including rare, large settlement events with high statistical leverage), there was no relationship between the estimated proportion of larvae that settled very quickly and settlement density across both sites $\left(F_{1,22}=0.009, \mathrm{p}=0.93\right)$. There was of course still a positive relationship between the proportion of lar-

Table 3. Bugula neritina. Jack-knifed classification success of a linear discriminant analysis of lophophore volume with known larval durations. The 3 groupings of dispersal duration were calculated using a regression tree

\begin{tabular}{|c|c|c|c|c|c|}
\hline \multirow[t]{2}{*}{$\begin{array}{l}\text { Actual dispersal } \\
\text { duration group }\end{array}$} & \multicolumn{4}{|c|}{$\begin{array}{l}\text { Predicted dispersal duration group } \\
\text { Total number (proportion) }\end{array}$} & \multirow{2}{*}{$\begin{array}{c}\text { Classification } \\
\text { success } \\
(\%)\end{array}$} \\
\hline & $0-1.5 \mathrm{~h}$ & $1.5-6.5 \mathrm{~h}$ & $6.5-32 \mathrm{~h}$ & Sums & \\
\hline $0-1.5 \mathrm{~h}$ & $81(0.75)$ & $22(0.2)$ & $5(0.05)$ & 108 & 75.00 \\
\hline $1.5-6.5 \mathrm{~h}$ & $36(0.33)$ & $47(0.44)$ & $25(0.23)$ & 108 & 44.44 \\
\hline $6.5-32 \mathrm{~h}$ & $4(0.04)$ & $22(0.24)$ & $67(0.72)$ & 93 & 72.04 \\
\hline Total & & & & 309 & 63.83 \\
\hline
\end{tabular}




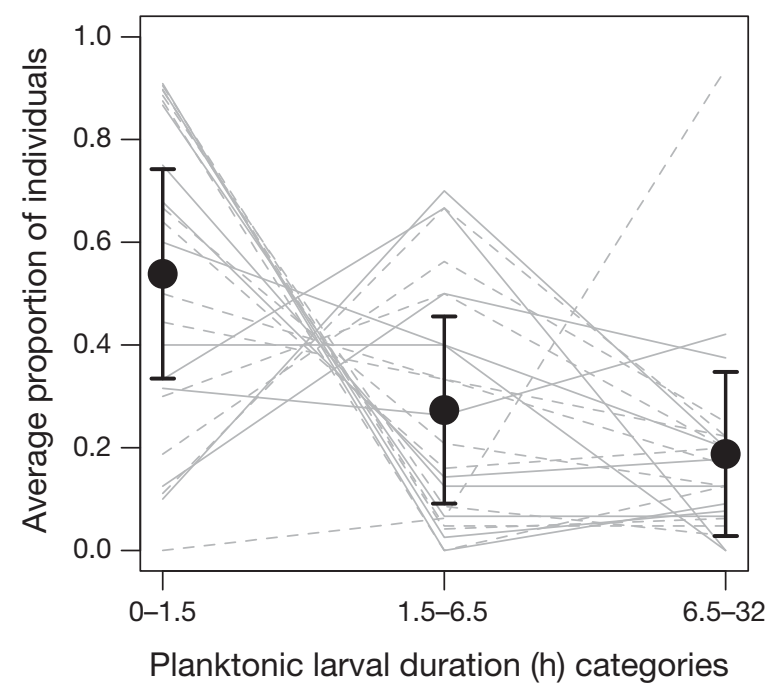

Fig. 4. Bugula neritina. Estimates of planktonic larval duration in the field. Estimates were based on linear discriminant analysis, where individuals that settled in the field were assigned to a larval duration category based on the volume of their lophophores, using the laboratory data as a 'training set' (see 'Materials and methods'). Larval duration categories were derived from a regression tree (Fig. 3). Lines join estimates on a given day at Manly (-) and Redcliffe (- - -). Circles ( $\pm 95 \%$ binomial CIs) represent the mean proportion of individuals assigned to each larval duration category

vae that settled quickly after release and settlement density at Manly $\left(F_{1,9}=7.74, \mathrm{p}=0.02\right)$. When the $2 \mathrm{~d}$ with exceptionally high settlement were excluded from the analysis (thereby making inferences over common, or $80 \%$ of, settlement densities at the 2 sites), there was a positive relationship between the estimated proportion of larvae that settled very quickly after release and the intensity of settlement on that day (Table 4, Fig. 5). This effect was consistent across sites as indicated by the non-significant interaction between site and planktonic duration $\left(F_{1,19}=0.03, \mathrm{p}=0.86\right)$.

Table 4. Bugula neritina. Analysis of covariance (ANCOVA) on the relationship between the proportion of individuals with short $(\leq 1.5 \mathrm{~h})$ dispersal durations at each site (Manly or Redcliffe) with settlement density in the field (see Fig. 4). The interaction between proportion and site was removed after finding it was not significant $\left(F_{1,19}=0.03, \mathrm{p}=0.86\right)$

\begin{tabular}{|lrrrr|}
\hline Source & df & \multicolumn{1}{c}{ MS } & \multicolumn{1}{c|}{$F$} & $\mathrm{p}$ \\
\hline Proportion & 1 & 2029.23 & 11.92 & 0.003 \\
Site & 1 & 63.62 & 0.38 & 0.548 \\
Residual & 20 & 170.21 & & \\
\hline
\end{tabular}

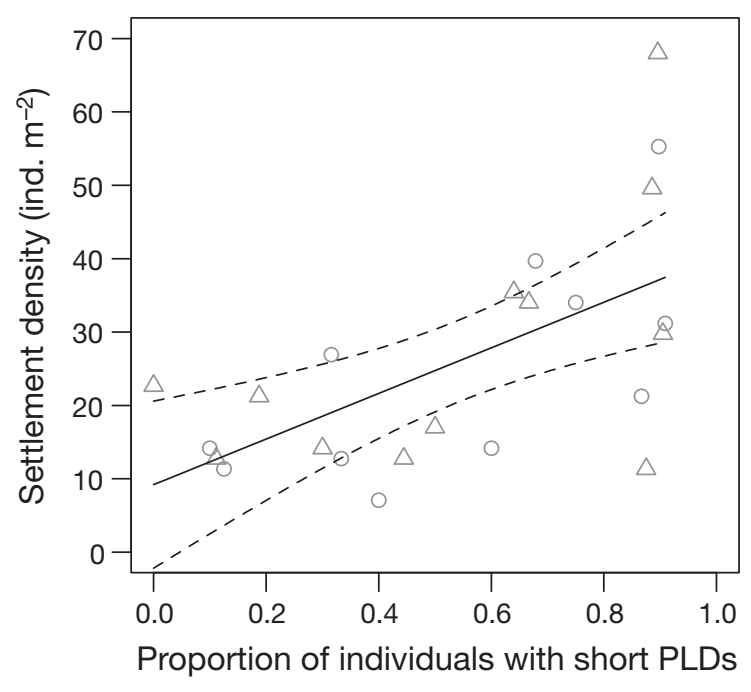

Fig. 5. Bugula neritina. Relationship between proportion of individuals with planktonic larval durations (PLDs) up to $1.5 \mathrm{~h}$ in the field and settlement density at Manly ( $\bigcirc)$ and Redcliffe $(\triangle)$. Each point represents a single day $(\mathrm{n}=23 \mathrm{~d})$. Dashed lines represent $95 \%$ CIs. Patterns were consistent between sites (see Table 4) $y=9.21+31.07 x_{i} F_{1,21}=12.29$, $\mathrm{p}=0.002 ; \mathrm{r}^{2}=0.34$. Two sampling days at Redcliffe with exceptionally high settlement (662 and 891 settlers $\mathrm{m}^{-2}$ ) at the end of the sampling period were removed

\section{DISCUSSION}

After establishing that lophophore volume in Bugula neritina was a good predictor of larval duration in the laboratory, we could successfully classify settlers in the field, based on their lophophore volumes, as spending a short $(<1.5 \mathrm{~h})$, intermediate $(1.5$ to $6.5 \mathrm{~h})$, or long $(>6.5 \mathrm{~h})$ period of time in the plankton. Despite being competent to settle upon release from the colony, a significant but variable proportion of larvae spent extended periods of time in the plankton. Some cohorts of larvae spent relatively little time in the plankton while other cohorts of larvae spent extended periods of time in the plankton. The extended planktonic periods that we predicted are likely to affect the dynamics of adult populations directly via reductions in settlement density, and indirectly via reductions in the post-settlement performance of individuals that experienced a metamorphic delay before settling.

While numerous studies have illustrated that delays in metamorphosis can affect the postmetamorphic performance of species with nonfeeding larvae (e.g. Pechenik 2006 and references therein), there are few estimates of delayed metamorphosis in the field (Pechenik 1986, Victor 1986a, Takami et al. 2006). Our results suggest that natu- 
rally settling larvae often experience delays in metamorphosis that are sufficient to strongly affect postsettlement performance. An earlier study on Bugula neritina at one of our field sites found that extending the larval period strongly affected post-metamorphic performance and that delays of more than a few hours dramatically reduced reproductive output (Burgess \& Marshall 2011a). The results presented here show that delay periods of more than a few hours occurred in almost every cohort we sampled in the field, which suggest that delays in metamorphosis are probably a major influence on adult population dynamics. Field estimates of delayed metamorphosis together with estimates of post-settlement performance remain very rare, and further studies will determine whether our findings are representative of other sites and species. More generally, it has become increasingly apparent that marine populations are driven not only by the numbers of settling larvae, but also by the quality of settling larvae (e.g. Moran \& Emlet 2001, Phillips 2002, Jarrett 2003, Sponaugle \& Grorud-Covert 2006, Hamilton et al. 2008, Shima \& Swearer 2009a, Burgess \& Marshall 2011a). Cohorts of settling larvae in both invertebrates and fish can vary enormously in their capacity to survive and reproduce, and explicit theoretical considerations of variation in larval phenotypes is now required (Schluter et al. 1991, Kinnison \& Hairston 2007, Chevin et al. 2010).

The distribution of PLDs in the field that we estimated have 3 (non-mutually exclusive) possible explanations. First, because it takes a longer amount of time to travel to more distant sites (Kinlan \& Gaines 2003, Largier 2003, Shanks et al. 2003, Siegel et al. 2003), the distribution of dispersal durations could reflect the spatial pattern of source locations of larvae. Individuals with shorter larval durations may have come from relatively closer sites and individuals with longer durations could come from more distant sites. Second, oceanographic features could drive the delivery of larvae to settlement sites, in which case larval durations may not reflect the distance at which larvae originated from, but reflect the amount of time that larvae get 'trapped' in oceanographic features (Siegel et al. 2008), or advected from and to settlement sites by oscillating tidal currents (Whitlatch \& Osman 1998). Such a scenario seems unlikely in our system, where water movement is highly limited within the marina environment (S. C. Burgess pers. obs.). The above 2 explanations involve larvae being unable to access settlement surfaces either because they must first travel from a distant point of release or because hydrodynamic features prevent larvae from accessing substrates. A third possible explanation for the distribution of larval durations could be that larvae were able to access settlement surfaces but did not settle because most surfaces were either inappropriate (e.g. covered by another species or sediment), or the surfaces were suitable post-settlement habitats, but larvae rejected the surfaces (e.g. 'choosiness' over a lack of settlement cues; Marshall \& Keough 2003, Botello \& Krug 2006, Burgess et al. 2009). Given that smaller larvae tend to settle sooner in our species (Marshall \& Keough 2003), it would also be interesting to know if smaller larvae contributed to the shorter larval durations and larger larvae contributed to the longer larvae durations. Given that our data suggest that some larvae delayed settlement for extended periods of time such that they would have incurred significant post-metamorphic costs, we suspect that larval 'choosiness' does not explain our results, as aged larvae tend to accept much lower-quality settlement cues, particularly in Bugula neritina (Marshall \& Keough 2003, Gribben et al. 2006). Thus, we suggest that a lack of access to suitable settlement sites (e.g. the rarity of highquality settlement sites) appears to delay the settlement of a significant proportion of larvae within any one cohort. Among cohorts, however, it is possible that a combination of mechanisms drove the variation in the proportion of larvae that delayed settlement.

We found that extended planktonic periods in the field were correlated with reductions in settlement density. This relationship occurred at Manly, and across both sites during common levels of settlement. Similar relationships between recruitment intensity and larval quality have been found or suggested in other systems (e.g. Leggett \& Frank 2008, Shima \& Swearer 2009b) and are likely to be important for population dynamics (Burgess \& Marshall 2011a,b). A number of factors could have influenced the correlation between the density of settlers and the estimated time that those settlers spent in the plankton as larvae. First, given that there are durationdependent costs of dispersal (Marshall \& Keough 2003, Burgess \& Marshall 2011a), when conditions were conducive to shorter periods in the plankton (e.g. periods of lower water movement), reproductive colonies may have released larger numbers of larvae, which in turn increased the intensity of settlement. Though we currently lack sufficient information on the drivers of spawning patterns in Bugula neritina at our field site (though see Cancino et al. 1991, Kosman \& Pernet 2009) to test the variable release rate hypo- 
thesis, we suspect that the indirect influence of variable larval release rates is an unlikely explanation for our results. Alternatively, the relationship between settlement density and larval durations may be directly coupled. Cohorts of larvae that spent more time in the plankton could have either originated from spawning populations that were further away or come from the same spawning population(s), but spent more time in the plankton before settling. Either way, both increased dispersal distances and extended exposure to planktonic sources of mortality will decrease cohort abundance through dilution and depletion. Genetic analyses would be extremely valuable in determining whether lower-density cohorts that spent more time in the plankton also originated from more distant populations (Palumbi 2003, David et al. 2010). Regardless of the underlying mechanism, there was a significant covariance between the intensity of settlement in any one cohort, and the experience of that cohort as larvae, and both larval quantity and quality are likely to affect the subsequent dynamics of the adult population (Hamilton et al. 2008, Shima \& Swearer 2009b, Burgess \& Marshall 2011a).

Our results provide some insights into the level of mortality that larvae experience while in the plankton. We found that, on average, the proportion of settlers with long planktonic durations (6.5 to $32 \mathrm{~h}$ ) was $35 \%$ of that for settlers with short durations (18.79/53.86). Instantaneous mortality rate can be estimated as $-(\log [s] / t)$, where $s$ is the proportion of individuals that survived and $t$ is the PLD. Assuming that our settlement plates sampled the larval population in an unbiased way, our results suggest an upper instantaneous mortality rate of 16 and $3 \%$ of the population per hour, after 6.5 or $32 \mathrm{~h}$, respectively (where $s=0.35$ and $t=6.5$ and $32 \mathrm{~h}$, respectively). These estimates of mortality rates are much higher than previous estimates for other, more conspicuous lecithotrophs (Morgan 1995). Our estimates of mortality should be treated with caution, however, as these planktonic mortality estimates assume no dilution effects, which are likely to increase with time.

What other sources of variation could have contributed to variation in lophophore size? Larval size and water temperature are obvious potential sources of variability in lophophore size, and may have contributed to the $<100 \%$ classification success. Kosman \& Pernet (2011) showed that lophophore volume increases with larval volume in several species of bryozoans in California, including Bugula neritina. We found no effect of larval volume on lophophore vol- ume at our field sites despite relatively high levels of replication and repeated trials. It is unclear what drove the differences between our study and that of Kosman \& Pernet (2011), but it could simply be that the relationship between larval volume and lophophore volume varies across oceans. Future studies at other sites will need to estimate any effects of larval volume before being able to use lophophore volume to predict planktonic durations. Furthermore, temperature could influence lophophore size directly via changes in growth rate (Takami et al. 2006, Kingsolver \& Huey 2008), or indirectly via changes in energy use during the larval stage that would be used for lophophore development (Jaeckle 1994, Wendt 2000). Future studies partitioning the effects of other sources of variability in lophophore size may decrease the uncertainty of predicted PLDs in the field.

We applied a novel technique to estimate PLDs in the field and our study is one of the few to provide estimates of pelagic larval duration in a marine invertebrate (Pechenik 1986, Takami et al. 2006). Despite being competent to settle immediately upon release, a significant but variable proportion of larvae spent extended periods of time in the plankton. While larval durations in the order of hours may not seem significantly long compared to planktotrophic species, they are long enough to have consequences for larval behaviour (Burgess et al. 2009) and post-settlement performance in Bugula neritina and other species with non-feeding larvae (Wendt 1998, Marshall et al. 2003, Burgess \& Marshall 2011a). Furthermore, while larval dispersal distances after several hours are likely to be in the order of metres to $10 \mathrm{~s}$ of metres, they are likely to be important for the genetic and demographic structure of some marine invertebrate populations (Osman \& Whitlatch 1998, Kinlan et al. 2005, David et al. 2010). Overall, the use of relative sizes of post-metamorphic feeding structures represents a promising approach for addressing a range of questions related to estimating the PLDs in species with non-feeding larvae. Given that estimating PLDs remains one of the great challenges in marine ecology for most organisms, we hope that this approach may prove useful for other species.

Acknowledgements. We thank the Moreton Bay Boat Club and the East Coast Marina for allowing us access to the floating docks. We also thank B. Galletly, K. Baker, and L. Barr for help collecting some of the Manly data. Two anonymous reviewers also provided thoughtful comments that improved the quality of the final submission. Financial support was provided by an Australian Research Council grant to D.J.M. and M. J. Keough. S.C.B. was supported in part by a Commonwealth Scientific and Industrial Research Organisation (CSIRO) top-up scholarship. 


\section{LITERATURE CITED}

Becker BJ, Levin LA, Fodrie FJ, McMillan PA (2007) Complex larval connectivity patterns among marine invertebrate populations. Proc Natl Acad Sci USA 104: 3267-3272

Bennett CE, Marshall DJ (2005) The relative energetic costs of the larval period, larval swimming and metamorphosis for the ascidian Diplosoma listerianum. Mar Freshw Behav Physiol 38:21-29

Bingham BL, Young CM (1991) Larval behavior of the ascidian Ecteinascidia turbinata Herdman: an in situ experimental study of the effects of swimming on dispersal. J Exp Mar Biol Ecol 145:189-204

> Botello G, Krug PJ (2006) 'Desperate larvae' revisited: age, energy and experience affect sensitivity to settlement cues in larvae of the gastropod Alderia sp. Mar Ecol Prog Ser 312:149-159

Botsford LW, White JW, Coffroth MA, Paris CB and others (2009) Connectivity and resilience of coral reef metapopulations in marine protected areas: matching empirical efforts to predictive needs. Coral Reefs 28:327-337

> Brothers E, Williams DM, Sale P (1983) Length of larval life twelve families of fishes at 'One Tree Lagoon' Great Barrier Reef, Australia. Mar Biol 76:319-324

> Burgess SC, Marshall DJ (2011a) Are numbers enough? Colonizer phenotype and abundance interact to affect population dynamics. J Anim Ecol 80:681-687

- Burgess SC, Marshall DJ (2011b) Temperature-induced maternal effects and environmental predictability. J Exp Biol 214:2329-2336

Burgess SC, Hart SP, Marshall DJ (2009) Pre-settlement behavior in larval bryozoans: the roles of larval age and size. Biol Bull (Woods Hole) 216:344-354

Cancino JM, Hughes RN, Ramirez C (1991) Environmental cues and the phasing of larval release in the bryozoan Celleporella hyalina. Proc R Soc Lond B 246:39-45

> Chevin LM, Lande R, Mace GM (2010) Adaptation, plasticity, and extinction in a changing environment: towards a predictive theory. PLoS Biol 8:e1000357 doi:10.1371/ journal.pbio. 1000357

- Cowen RK, Paris CB, Srinivasan A (2006) Scaling of connectivity in marine populations. Science 311:522-527

David GK, Marshall DJ, Riginos C (2010) Latitudinal variability in spatial genetic structure in the invasive ascidian, Styela plicata. Mar Biol 157:1955-1965

> Davis AR, Butler AJ (1989) Direct observation of larval dispersal in the colonial ascidian Podoclavella moluccensis Sluiter: evidence for closed populations. J Exp Mar Biol Ecol 127:189-203

- De'ath G, Fabricius KE (2000) Classification and regression trees: A powerful yet simple technique for ecological data analysis. Ecology 81:3178-3192

Gerrodette T (1981) Dispersal of the solitary coral Balanophyllia elegans by demersal planular larvae. Ecology 62: 611-619

Gonzalez AF, Otero J, Pierce GJ, Guerra A (2010) Age, growth, and mortality of Loligo vulgaris wild paralarvae: implications for understanding of the life cycle and longevity. ICES J Mar Sci 67:1119-1127

> Gribben PE, Marshall DJ, Steinberg PD (2006) Less inhibited with age? Larval age modifies responses to natural settlement inhibitors. Biofouling 22:101-106

> Hamilton SL, Regetz J, Warner RR (2008) Postsettlement survival linked to larval life in a marine fish. Proc Natl Acad
Sci USA 105:1561-1566

> Holt RD, Gaines MS (1992) Analysis of adaptation in heterogeneous landscapes: implications for the evolution of fundamental niches. Evol Ecol 6:433-447

> Hunter E, Okano K, Tomono Y, Fusetani N (1998) Functional partitioning of energy reserves by larvae of the marine bryozoan Bugula neritina (L.). J Exp Biol 201:2857-2865

Jaeckle WB (1994) Rates of energy consumption and aquisition by lecithotrophic larvae of Bugula neritina (Bryozoa, Cheilostomata). Mar Biol 119:517-523

Jarrett JN (2003) Seasonal variation in larval condition and postsettlement performace of the barnacle Semibalanus balanoides. Ecology 84:384-390

Jones GP, Planes S, Thorrold SR (2005) Coral reef fish larvae settle close to home. Curr Biol 15:1314-1318

Kingsolver JG, Huey RB (2008) Size, temperature, and fitness: three rules. Evol Ecol Res 10:251-268

- Kinlan BP, Gaines SD (2003) Propagule dispersal in marine and terrestrial environments: a community perspective. Ecology 84:2007-2020

Kinlan BP, Gaines SD, Lester SE (2005) Propagule dispersal and the scales of marine community process. Divers Distrib 11:139-148

Kinnison MT, Hairston NG (2007) Eco-evolutionary conservation biology: contemporary evolution and the dynamics of persistence. Funct Ecol 21:444-454

> Kosman ET, Pernet B (2009) Diel variation in the sizes of larvae of Bugula neritina in field populations. Biol Bull (Woods Hole) 216:85-93

Kosman ET, Pernet B (2011) Intraspecific variation in larval size and its effects on juvenile lophophore size in four bryozoans. Mar Ecol Prog Ser 429:67-73

> Laptikhovsky VV, Arkhipkin AI, Golub AA (1993) Larval age, growth, and mortality in the oceanic squid Stenoteuthis pteropus (Cephalopoda, Ommastrephidae) from the eatern tropical Atlantic. J Plankton Res 15:375-384

> Largier JL (2003) Considerations in estimating larval dispersal distances from oceanographic data. Ecol Appl 13(Suppl):71-89

> Leggett WC, Frank KT (2008) Paradigms in fisheries oceanography. Oceanogr Mar Biol Annu Rev 46:331-364

Lenormand T (2002) Gene flow and the limits to natural selection. Trends Ecol Evol 17:183-189

Levin LA (2006) Recent progress in understanding larval dispersal: new directions and digressions. Integr Comp Biol 46:282-297

Marshall DJ, Keough MJ (2003) Variation in the dispersal potential of non-feeding invertebrate larvae: the desperate larva hypothesis and larval size. Mar Ecol Prog Ser 255:145-153

Marshall DJ, Pechenik JA, Keough MJ (2003) Larval activity levels and delayed metamorphosis affect post-larval performance in the colonial, ascidian Diplosoma listerianum. Mar Ecol Prog Ser 246:153-162

> Miller SE (1993) Larval period and its influence on postlarval life history: comparison of lecithotrophy and facultative planktotrophy in the aeolid nudibranch Phestilla sibogae. Mar Biol 117:635-645

Miller KJ (1998) Short-distance dispersal of black coral larvae: inference from spatial analysis of colony genotypes. Mar Ecol Prog Ser 163:225-233

Moran AL, Emlet RB (2001) Offspring size and performance in variable environments: field studies on a marine snail. Ecology 82:1597-1612

Morgan SG (1995) Life and death in the plankton: larval 
mortality and adaptation. In: McEdward L (ed) Ecology of marine invertebrate larvae. CRC Press, Boca Raton, FL, p 279-321

Olson RR (1985) The consequences of short-distance larval dispersal in a sessile marine invertebrate. Ecology 66: 30-39

Osman RW, Whitlatch RB (1998) Local control of recruitment in an epifaunal community and the consequences to colonization processes. Hydrobiologia 375/376:113-123

> Palmer AR, Strathmann RR (1981) Scale of dispersal in varying environments and its implications for life-histories of marine invertebrates. Oecologia 48:308-318

$>$ Palumbi SR (2003) Population genetics, demographic connectivity, and the design of marine reserves. Ecol Appl 13(Suppl):146-158

Pannella G (1971) Fish otololiths: daily growth layers and periodical patterns. Science 173:1124-1127

Pechenik JA (1986) Field evidence for delayed metamorphosis of larval gastropods: Crepidula plana Say, C. fornicata (L.), and Bittium alternatum (Say). J Exp Mar Biol Ecol 97:313-319

> Pechenik JA (2006) Larval experience and latent effects metamorphosis is not a new beginning. Integr Comp Biol 46:323-333

> Pechenik JA, Cerulli TR (1991) Influence of delayed metamorphosis on survival, growth, and reproduction of the marine polychaete Capitella sp. I. J Exp Mar Biol Ecol 151:17-27

Pechenik JA, Wendt DE, Jarrett JN (1998) Metamorphosis is not a new beginning. Bioscience 48:901-910

Phillips NE (2002) Effects of nutrition-mediated larval condition on juvenile performance in a marine mussel. Ecology 83:2562-2574

Qian PY, Pechenik JA (1998) Effects of larval starvation and delayed metamorphosis on juvenile survival and growth of the tube-dwelling polychaete Hydroides elegans (Haswell). J Exp Mar Biol Ecol 227:169-185

Quinn GP, Keough MJ (2002) Experimental design and data analysis for biologists. Cambridge University Press, New York, NY

> Ronce O (2007) How does it feel to be like a rolling stone? Ten questions about dispersal evolution. Annu Rev Ecol Evol Syst 38:231-253

Rumrill SS (1989) Natural mortality of marine invertebrate larvae. Ophelia 32:163-198

Schluter D, Price TD, Rowe L (1991) Conflicting selection pressures and life-history trade-offs. Proc R Soc Lond B 246:11-17

Shanks AL, Grantham BA, Carr MH (2003) Propagule dispersal distance and the size and spacing of marine reserves. Ecol Appl 13(Suppl):159-169

Shima JS, Swearer SE (2009a) Larval quality is shaped by matrix effects: implications for connectivity in a marine metapopulation. Ecology 90:1255-1267

Shima JS, Swearer SE (2009b) Spatially variable larval histories may shape recruitment rates of a temperate reef fish. Mar Ecol Prog Ser 394:223-229

Siegel DA, Kinlan BP, Gaylord B, Gaines SD (2003) Lagrangian descriptions of marine larval dispersion. Mar Ecol Prog Ser 260:83-96

Siegel DA, Mitarai S, Costello CJ, Gaines SD, Kendall BE, Warner RR, Winters KB (2008) The stochastic nature of

Editorial responsibility: Steven Morgan,

Bodega Bay, California, USA larval connectivity among nearshore marine populations. Proc Natl Acad Sci USA 105:8974-8979

Sponaugle S, Cowen RK (1997) Early life history traits and recruitment patterns of Caribbean wrasses (Labridae). Ecol Monogr 67:177-202

Sponaugle S, Grorud-Covert K (2006) Environmental variability, early life-history traits, and survival of new coral reef fish recruits. Integr Comp Biol 46:623-633

> Stoner DS (1992) Vertical distribution of a colonial ascidian on a coral reef: the roles of larval dispersal and lifehistory variation. Am Nat 139:802-824

- Strathmann RR (1974) The spread of sibling larvae of sedentary marine invertebrates. Am Nat 108:29-44

Strathmann RR (1985) Feeding and non-feeding larval development and life history evolution in marine invertebrates. Annu Rev Ecol Syst 16:339-361

> Swearer SE, Caselle JE, Lea DW, Warner RR (1999) Larval retention and recruitment in an island population of a coral-reef fish. Nature 402:799-802

Takami H, Oshino A, Sasaki R, Fukazawa H, Kawamura T (2006) Age determination and estimation of larval period in field caught abalone (Haliotis discus hannai Ino 1953) larvae and newly metamorphosed post-larvae by counts of radular teeth rows. J Exp Mar Biol Ecol 328:289-301

Thorson G (1950) Reproductive and larval ecology of marine bottom invertebrates. Biol Rev Camb Philos Soc 25:1-45

> Vance RR (1973) Reproductive strategies in marine benthic invertebrates. Am Nat 107:339-352

Venables WN, Ripley BD (2002) Modern applied statistics with S. Springer, New York, NY

Victor BC (1986a) Delayed metamorphosis with reduced larval growth in a coral reef fish (Thalassoma bifasciatum). Can J Fish Aquat Sci 43:1208-1213

Victor BC (1986b) Duration of the planktonic larval stage of one hundred species of Pacific and Atlantic wrasses (family Labridae). Mar Biol 90:317-326

- Villanueva R, Arkhipkin A, Jereb P, Lefkaditou E and others (2003) Embryonic life of the loliginid squid Loligo vulgaris: comparison between statoliths of Atlantic and Mediterranean populations. Mar Ecol Prog Ser 253: 197-208

Wendt DE (1996) Effect of larval swimming duration on success of metamorphosis and size of the ancestrular lophophore in Bugula neritina (Bryozoa). Biol Bull (Woods Hole) 191:224-233

Wendt DE (1998) Effect of larval swimming duration on growth and reproduction of Bugula neritina (Bryozoa) under field conditions. Biol Bull (Woods Hole) 195: 126-135

Wendt DE (2000) Energetics of larval swimming and metamorphosis in four species of Bugula (Bryozoa). Biol Bull (Woods Hole) 198:346-356

Whitlatch RB, Osman RW (1998) A new device for studying benthic invertebrate recruitment. Limnol Oceanogr 43: 516-523

> Woollacott RM, Pechenik JA, Imbalzano KM (1989) Effects of duration of larval swimming period on early colony development in Bugula stolonifera (Bryozoa: Cheilostomata). Mar Biol 102:57-63

Young CM (1986) Direct observations of field swimming behavior in larvae of the colonial ascidian Ecteinascidia turbinata. Bull Mar Sci 39:279-289

Submitted: June 7, 2011; Accepted: August 29, 2011

Proofs received from author(s): October 19, 2011 